\title{
Achieving Superplasticity in Fine-Grained Al-Mg-Sc Alloys
}

\author{
Pedro H.R. Pereira ${ }^{1, a}$, Yi Huang ${ }^{2, b}$, Megumi Kawasaki ${ }^{3, c}$ \\ and Terence G. Langdon, ${ }^{4, \mathrm{~d}}$ * \\ ${ }^{1}$ Metallurgical and Materials Engineering, Universidade Federal de Minas Gerais, \\ Belo Horizonte, MG 31270-901, Brazil \\ ${ }^{2}$ Design and Engineering, Faculty of Science and Technology, Bournemouth University, \\ Poole, Dorset BH12 5BB, U.K. \\ ${ }^{3}$ Mechanical, Industrial and Manufacturing Engineering, Oregon State University, \\ Corvallis, OR 97331-6001, U.S.A. \\ ${ }^{4}$ Materials Research Group, Department of Mechanical Engineering, \\ University of Southampton, Southampton SO17 1BJ, U.K. \\ appereira@demet.ufmg.br, byhuang2@bournemouth.ac.uk, 'cmegumi.kawasaki@oregonstate.edu, \\ dangdon@soton.ac.uk
}

Keywords: Equal-channel angular pressing, Friction stir processing, High-pressure torsion, Severe plastic deformation, Superplasticity.

\begin{abstract}
Superplasticity denotes the ability of a limited number of materials to achieve exceptionally high tensile elongations of at least $400 \%$. Experiments show that the Al-Mg-Sc alloys provide excellent capabilities for achieving superplastic flow and also they can be formed easily in biaxial superplastic forming operations. It is important, therefore, to examine the superplastic flow mechanism when the alloy is prepared using different procedures. This report examines the superplastic characteristics of these alloys after preparation without subjecting to any severe plastic deformation (SPD), after processing using the two SPD procedures of equal-channel angular pressing (ECAP) and high-pressure torsion (HPT) and after processing using the alternative procedure of friction stir processing (FSP). The results are compared using each technique and they are examined with reference to a theoretical model that was developed specifically for superplastic flow in conventional alloys.
\end{abstract}

